\title{
What scares a mussel? Changes in valve movement pattern as an immediate response of a byssate bivalve to biotic factors
}

\author{
Anna Dzierżyńska-Białończyk (iD) Eukasz Jermacz • Joanna Zielska • \\ Jarosław Kobak
}

Received: 16 October 2018/Revised: 6 June 2019/Accepted: 22 June 2019/Published online: 10 July 2019

(C) The Author(s) 2019

\begin{abstract}
Responsiveness to biotic factors is crucial for the survival of sessile aquatic animals. They cannot escape from danger, but developed a number of defences against predation, usually delayed in time. We checked the initial defence of the freshwater byssate zebra mussel, Dreissena polymorpha, associated with valve gaping. We tested the effect of chemical signals: fish predator scent (the roach Rutilus rutilus), conspecific alarm cue and a mixture of both, as well as a mechanical stimulus: the presence of an amphipod (Dikerogammarus villosus) mechanically irritating mussels. The alarm cues and amphipod presence made mussels spend more time with closed/narrowly open valves, which can be related to decreasing detection probability by reduced infochemical excretion and/or protecting soft tissues in the presence of an imminent threat. In contrast, reactions to the predator scent alone were much weaker. Moreover, the fish scent mixed with alarm
\end{abstract}

Handling editor: Manuel Lopes Lima

Electronic supplementary material The online version of this article (https://doi.org/10.1007/s10750-019-04007-0) contains supplementary material, which is available to authorized users.

A. Dzierżyńska-Białończyk $(\bowtie) \cdot$ Ł. Jermacz ·

J. Zielska · J. Kobak

Department of Invertebrate Zoology, Faculty of Biology

and Environmental Protection, Nicolaus Copernicus

University, Lwowska 1, 87-100 Torun, Poland

e-mail: adb@doktorant.umk.pl substance induced weaker responses than the alarm substance alone. Thus, the fish infochemical might mask the presence of the alarm cue components, potentially benefiting the predator. A variety of defences exhibited by mussels demonstrates the importance of the predation cue type (direct/indirect, chemical/mechanical, originating from conspecifics/ predators/mixed) for the behaviour of sessile animals.

Keywords Valve gaping Dreissena polymorpha . Predation cues · Activity $\cdot$ Induced defence

\section{Introduction}

Aquatic sessile species are ecologically and economically important as ecosystem engineers, fouling community members and nuisance for submerged equipment (Khalaman, 2001; Sousa et al., 2009). Their responses to environmental factors differ from those exhibited by mobile animals. With no or limited relocation capabilities they can react by withdrawing into their shells or shelters and modifying their activity (Reimer \& Tedengren, 1997; Kobak et al., 2010; Naddafi \& Rudstam, 2013). On the other hand, prolonged activity is crucial for their survival as most of them are filter-feeders, relying on constant pumping of water into their filtering structures (Gosling, 2003).

One of the factors most affecting animal behaviour is the presence of predators (Lima \& Dill, 1990; 
Ferrari et al., 2009). Common defensive reactions of animals are active avoidance (Lima \& Dill, 1990; Wisenden \& Millard, 2001; Jermacz et al., 2015) and/ or taking an appropriate shelter (Schmidt-Drewello et al., 2016). However, sessile organisms developed more sophisticated and less conspicuous responses. Depending on evolutionary constraints and predator hunting modes, they can more strongly adhere to the substratum (Shin et al., 2008; Cheung et al., 2009), reduce feeding rates (Naddafi et al., 2007), develop harder shells (Czarnołęski et al., 2006), produce toxins (Hill et al., 2005) and/or select sheltered sites during their mobile phase of life (Bryan et al., 1998; Dahms et al., 2004). These responses may vary depending on the quality of the predation cue, ranging from predator kairomones (depending on their diet and hunger level) to alarm substances produced by wounded conspecifics (indicating a more direct danger: a currently foraging predator) (Smee \& Weissburg, 2006; Large et al., 2012; Jermacz et al., 2017). Furthermore, prey reactions vary with time, different measures being induced immediately after the detection of predation cues and during the chronic exposure to predator pressure (Reimer \& Tedengren, 1997; Turner et al., 2006).

Moreover, sessile species are exposed to the impact of mobile non-predatory organisms occupying their colonies in great numbers (Botts et al., 1996). Being attached to the substratum, they have limited capability of avoiding scraping and tickling by specimens moving over their bodies, which can negatively affect their activity and condition, sometimes resembling the effect of predation cues (Kobak et al., 2012). Both predators and cohabiting organisms form a natural biotic environment of sessile organisms. In the field, various stimuli may create conflicting situations (when protection against one danger increases exposure to another) or act synergistically, optimizing responses to different risk sources (Wudkevich et al., 1997; Beggel et al., 2016). Therefore, the knowledge how they respond to these factors is crucial for understanding their functioning, impact on the environment and relationships with other species.

One of the most common freshwater sessile species is the zebra mussel, Dreissena polymorpha (Pallas, 1771). Although a hard shell defends it from most of its potential predators, it constitutes a considerable diet item for several fishes (Prejs et al., 1990; Naddafi \& Rudstam, 2013). In the presence of predators, mussels increase their attachment (Kobak et al., 2010; Naddafi \& Rudstam, 2013), aggregation (Naddafi \& Rudstam, 2013) and shell strength (Czarnołęski et al., 2006; Naddafi \& Rudstam, 2014). These changes increase predator handling costs (Prejs et al., 1990; Czarnołęski et al., 2006), but develop over a relatively long time ( $>4$ days) (Kobak \& Kakareko, 2009; Kobak et al., 2012; Naddafi \& Rudstam, 2013, 2014). Quite similar responses of zebra mussels (increase in attachment strength, reduction in upward movement) to the presence of gammarid amphipods occupying mussel colonies were also observed (Kobak et al., 2012). These animals are not considered a direct threat to mussels, but they may mechanically irritate mussel soft tissues and affect their responses to other environmental factors. The unresolved question is whether and how D. polymorpha reacts to these nuisance cues immediately after the signal reception. To answer this question, we checked mussel valve movements. They are associated with all life activities of mussels, such as nutrition, respiration, reproduction, excretion and signal reception (Gosling, 2003; García-March et al., 2008). Their feeding efficiency is directly related to the degree of valve gaping, regulating the pumping rate (Jørgensen et al., 1988; Newell et al., 1998; Riisgård et al., 2003; Saurel et al., 2007). In optimal environmental conditions, a mussel spends most of the time with open valves (Jørgensen et al., 1988; Kramer \& Foekema, 2001). Thus, prolonged disturbance in valve opening may negatively affect mussel condition. In urgent stress situations, one of the fastest mussel reactions is valve closing (Borcherding, 2006), which reduces its contacts with the environment: both in terms of intaking potentially harmful substances (Rajagopal et al., 1997) as well as releasing chemical and mechanical cues that could be used by enemies to locate the sender (Antoł et al., 2018). Thus, reduction in valve gaping can be a potential defensive response regardless of the predator hunting mode.

In the present study, we checked short-time valve movement responses of $D$. polymorpha to predation cues and physical presence of non-predatory organisms occupying mussel beds. We tested mussel reactions to the kairomone of the roach Rutilus rutilus (Linnaeus, 1758). This fish is an efficient molluscivore (Prejs et al., 1990) and defensive responses of $D$. polymorpha to its kairomones have been found in previous studies (e.g. Naddafi et al., 2007; Kobak et al., 2010). The fish were fed with mussels or neutral 
food (chironomid larvae) to check for the potential impact of dietary cues in predator exudates (Chivers et al., 1996; Wisenden, 2015). Predation is connected with alarm substances released by crushed prey; thus, we also used this stimulus in our study. We hypothesized that all these chemical stimuli would decrease time spent with widely open valves and frequency of valve movements, which would be beneficial in terms of "chemical hiding" from a predator (Antoł et al., 2018). We also intended to check whether a mixture of predation cues (conspecific alarm substance, predator dietary cues and/or kairomone) would increase synergistically the magnitude of mussel reactions. Additionally, we checked the effects of the presence of a Ponto-Caspian gammarid Dikerogammarus villosus (Sowinsky, 1894), occupying D. polymorpha colonies (Devin et al., 2003). We supposed that gammarids might irritate soft parts of siphons and mantle surface and finally induce valve closing similarly to the aforementioned predation cues. If so, we intended to compare the relative strength of responses to predation and gammarid cues.

\section{Materials and methods}

Animal collection and housing

All experiments were conducted under laboratory conditions, using D. polymorpha, roach $R$. rutilus and gammarids collected from the Włocławek Reservoir (a dam lake located on the lower Vistula River, Central Poland) from a depth of ca. $2 \mathrm{~m}$ (flow velocity $<10 \mathrm{~cm} / \mathrm{s}$, Gierszewski, 2006) in October 2015 (temperature $10{ }^{\circ} \mathrm{C}$ ). D. polymorpha and D. villosus occupying mussel colonies were sampled from the reservoir bottom by a diver together with their substrata (unionid bivalves). D. polymorpha were removed from the unionids in situ and the later were immediately returned to the environment. Roach were captured by electrofishing, using a certified device IUP-12 (Radet, Poznań, Poland). Other fish were released after capture and recovered within a few minutes. Fish collection and use in the experiments were conducted under permit from the Local Ethic Committee (University of Science and Technology, Bydgoszcz, Poland) no. 21/2015. Animals were transported to the laboratory ( $2 \mathrm{~h}$ transport time) in 10-1 aerated plastic containers. All animals were kept for 2 weeks in single-species stock aquaria (all mussels: 350 L, 3 fish per 200 L, all gammarids: 150 L) supplied with aquarium filters and aerators. The water in aquaria had a constant temperature of $18{ }^{\circ} \mathrm{C}$ (sustained by air-conditioning). Mussels were fed every second day with $2 \mathrm{~g}$ of dried Chlorella sp. per 1000 individuals (Kilgour \& Baker, 1994). Fish were fed according to the experimental treatment (see below) and gammarids were fed every day with $4 \mathrm{~g}$ of frozen chironomid larvae. Ca. $30 \%$ of the water volume was changed on weekly basis and on the occasion of water collection for the purpose of the experiment (see below).

\section{Experimental design}

All tested mussels were collected from the top layer of druses formed on unionid shells to minimize the risk of their weak condition. Mussels were detached from their natural substrate by severing their byssal threads with a scalpel. $24 \mathrm{~h}$ before the experiments, mussels (length: 18-22 mm) were marked by a thin layer of a low-weight red plasticine (determined as the fastest and hence least invasive labelling method in preliminary trials), attached to the posterior part of one of the valves (Fig. 1). This mark allowed the behaviour analysis software to follow the video-recorded valve movements. Marked mussels were fastened to glass microscope slides with unreactive fast-binding methyl acrylic glue by the ventral surface of the non-marked

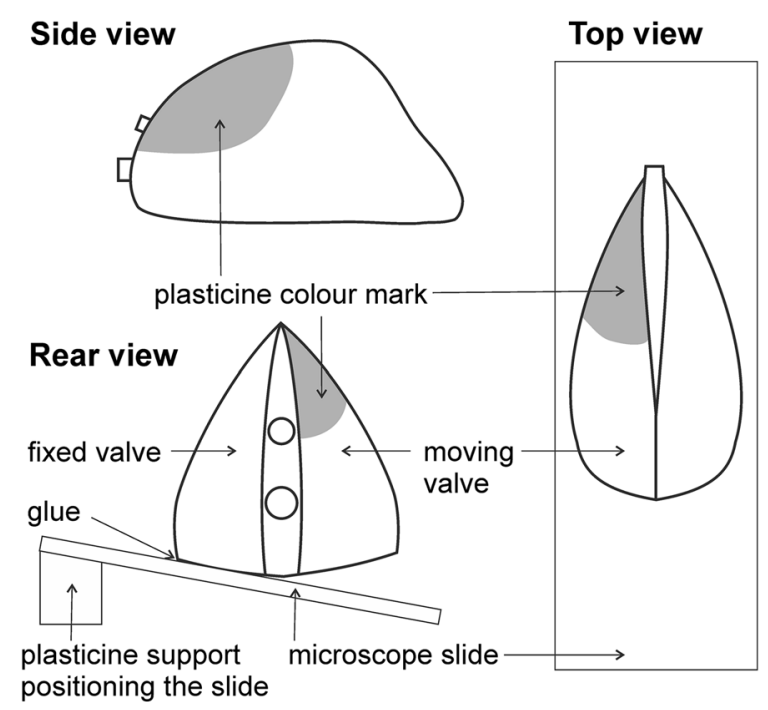

Fig. 1 Experimental setup 
valve to prevent them from relocating during the experiment (Fig. 1). In the wild, mussels are often immobilized by overgrowing conspecifics and spend most of their life attached to the substratum; thus, this situation is not unusual for them. All processed individuals were left to recover in a 150-1 stock tank for $24 \mathrm{~h}$ in the same conditions as those in experimental tanks. Only mussels which produced byssus threads after this time were used in the experiments.

The experiments were conducted in glass beakers (diameter: $140 \mathrm{~mm}$, height: $72 \mathrm{~mm}$ ) filled with $700 \mathrm{ml}$ of water. A microscope slide with a single mussel was placed in the beaker and positioned so that the mussel was located in a horizontal plane. The experimental beakers were cleaned, water changed and new individuals used for each replicate. Experimental treatments were replicated 19-25 times. This variability depended on the availability of suitable mussels (byssally attached after marking and widely open at least once during the entire experimental period) and number of successful trials (without technical errors, such as accidental detachment of the plasticine marker during the trial). Individuals that did not extend their siphons were also removed from the analysis as it could result from their poor physical condition or injury during the pre-experimental handling. After the visual inspection of the recordings ca. $5 \%$ of all trials were rejected due to the aforementioned reasons including only few cases of individuals that did not open their valves.

Mussels were placed in the beakers filled with water containing a particular stimulus (see below) and exposed for the next $2 \mathrm{~h} 15 \mathrm{~min}$. The first 15-min. period was considered as an acclimation time and excluded from the analysis. Disturbances resulting from handling during the stimulus application at the beginning of the experiment could interrupt mussel behaviour and in consequence responses to examined factors. During the next $2 \mathrm{~h}$ mussel valve movements were recorded from the top by video cameras (SNB6004, Samsung, South Korea).

The experiment consisted of seven treatments: (1) the conspecific alarm substance, (2) the scent of roach (kairomone) fed with chironomid larvae, (3) the scent of roach fed with D. polymorpha (kairomone and conspecific dietary cues), (4) the alarm substance and scent of roach fed with chironomids, (5) the alarm substance and scent of roach fed with mussels, (6) the presence of $D$. villosus and (7) control treatment without any cues. The alarm substance was a colourless filtered mixture of water and manually crushed mussels in volumetric proportion of 4:7. One $\mathrm{ml}$ of the alarm substance was added to the experimental beaker filled with control water to obtain the active concentration according to Toomey et al. (2002). The scent of the roach was applied by adding $700 \mathrm{ml}$ of water (i.e. the entire beaker volume) from a $200 \mathrm{~L}$ stock tank, in which three fish, $220 \mathrm{~mm}$ in length, had been incubated for 2 weeks, to the experimental beakers. The fish were fed once a day with $3 \mathrm{~g}$ of chironomid larvae or $3 \mathrm{D}$. polymorpha per individual. They were starved for $24 \mathrm{~h}$ before collecting water for the experiment to avoid the presence of signals from living mussels (not consumed yet) in the test. The control water was pre-conditioned for 2 weeks in the same tank as that used to incubate the fish, but devoid of mussels and predators. In the gammarid treatment, three D. villosus individuals (15-18 $\mathrm{mm}$ in length) were placed in the experimental arena and allowed to move freely among the mussels.

Water temperature (sustained by air-conditioning) during the experiments was $18{ }^{\circ} \mathrm{C}$. Illumination (necessary due to video recording) provided by incandescent light was 65 lx. Oxygen concentrations (measured with a multiparameter benchtop meter, inoLab Multi 9620 IDS, WTW, Poland connected with an optical sensor FDO 925, WTW, Poland) before and after the trials were $8.95 \pm 0.04$ and $8.85 \pm 0.08 \mathrm{mg} /$ 1 (mean $\pm \mathrm{SD}$ ), respectively, and did not differ among the experimental treatments.

\section{Data analysis}

We used Noldus Ethovision XT 10.1 software to quantify mussel behaviour on the basis of the recorded videos. Every second, we determined the position of the colour mark located on the movable mussel valve, relative to a constant point fixed on the other valve. Then, each valve position was expressed as the percentage of the maximum valve gaping observed for a given individual. We found no significant differences among the treatments in the maximum valve gaping (in $\mathrm{mm}$ ) observed for each individual, showing that they all exhibited their maximum gaping at some time during the exposure. Moreover, we found no correlation between maximum valve gaping and mussel size (within the range used in the experiments). This justifies the use of the percentage gaping as the 
optimum response variable. The obtained dataset was further processed with a custom-made application written in Visual Basic for Microsoft Excel to detect gradual changes in valve position (opening and closing movements) and stable periods spent at particular valve gaping ranges, as well as their parameters (rate, amplitude, duration) during the experiment. We considered two valve movements as separate when they were separated by a stable period lasting for at least $5 \mathrm{~s}$. We examined the following response variables: (1) Average valve gaping during the experiment; (2) Percentage of time spent by mussels with: (i) widely open valves $(>80 \%$ of the maximum valve gaping) (ii) narrowly open valves $(<20 \%)$ and (iii) totally closed valves (for better understanding of the average valve gaping value); (3) Number of valve opening movements. Visual inspection of the recordings indicated that mussels did not extend their siphons at valve gaping below $20 \%$. Such a detailed approach can potentially lead to detection of subtle mussel reactions to environmental factors, undetectable with methods using only binary valve states (closed/open shell). All these parameters were calculated separately for the first and second hour of the experiment in order to reflect the potential impact of time on mussel responses to experimental factors.

We applied a General Linear Model analysis to test the effect of experimental treatments on the average valve gaping and percentages of time spent by mussels in particular gaping ranges. The models included two fixed factors: treatment ( 7 levels: various predation or gammarid cues and control) and experiment duration (repeated measures factor: hour 1 and 2) as well as their interaction. Normality and homoscedasticity were checked with Shapiro-Wilk and Levene tests, respectively, and percentage time data were logtransformed to meet these assumptions. A Tukey HSD test was used as a post hoc procedure for significant main effects of treatment and a sequential Bonferronicorrected Fisher LSD test was applied for pairwise comparisons when an interaction was significant.

Numbers of valve opening movements were compared using a Generalized Linear Model (Poisson distribution, log-link function) including treatment, time (repeated measures) and their interaction. Sequential Bonferroni-corrected pairwise contrasts were used as a post hoc procedure.

The analyses were carried out using SPSS 25.0 statistical package (IBM Inc.).

\section{Results}

Average valve gaping during the experiment varied from 2 to $72 \%$ (Fig. 2) and significantly depended on experiment duration (valve gaping in the second hour of the experiment was by $10 \%$ higher than in the first hour) and on the cues (General Linear Model: Table 1A). Significantly lower valve gaping was observed in the presence of gammarids $(2-3 \%)$ and the alarm substance alone $(39-43 \%)$ relative to the control treatment (53-72\%).

The presence of gammarids, fish scents and/or alarm signals significantly affected the time spent by mussels with totally closed, narrowly open $(0-20 \%)$ or widely open $(>80 \%)$ valves (General Linear Model: Table 1B-D). Time spent by mussels with totally closed valves varied depending on experiment duration (a significant treatment $\mathrm{x}$ time interaction). The highest total closure times were observed in the presence of gammarids (34-48\% of the test duration), as well as, to a lesser extent and only during the first hour of the test, in the presence of the alarm substance alone $(2.5 \%)$ and in the control treatment $(1.8 \%)$ (Fig. 3A). The presence of fish scents (both diets) together with the alarm substance reduced the time spent with totally closed valves $(0.1-0.2 \%)$ compared to the treatments with both these stimuli applied separately (0.5-2.5\%).

Time spent by mussels with narrowly open valves $(<20 \%)$ depended on treatment only (General Linear Model: Table 1C). Mussels were narrowly open for a longer time in the presence of gammarids (95\% of test duration) and the alarm substance alone (12\%) (Fig. 3B). The shortest times spent with narrowly open valves were exhibited by mussels exposed to the fish scents (both diets) mixed with the alarm substance $(1.7-3.1 \%)$. Values observed in these treatments differed significantly from the corresponding treatments with the alarm substance absent (4.8-6.0\%).

Time spent with widely open valves $(>80 \%)$ depended on treatment only (General Linear Model: Table 1D) and was markedly lower in the presence of gammarids $(0.1 \%)$ and the alarm substance alone (12\%) (Fig. 3C). Moreover, this parameter was significantly lower in the presence of the alarm substance and the scent of fish fed with mussels (21\%) than in the control treatment (38\%).

The number of valve opening movements varied strongly among individuals, ranging from 1 to 816 per 


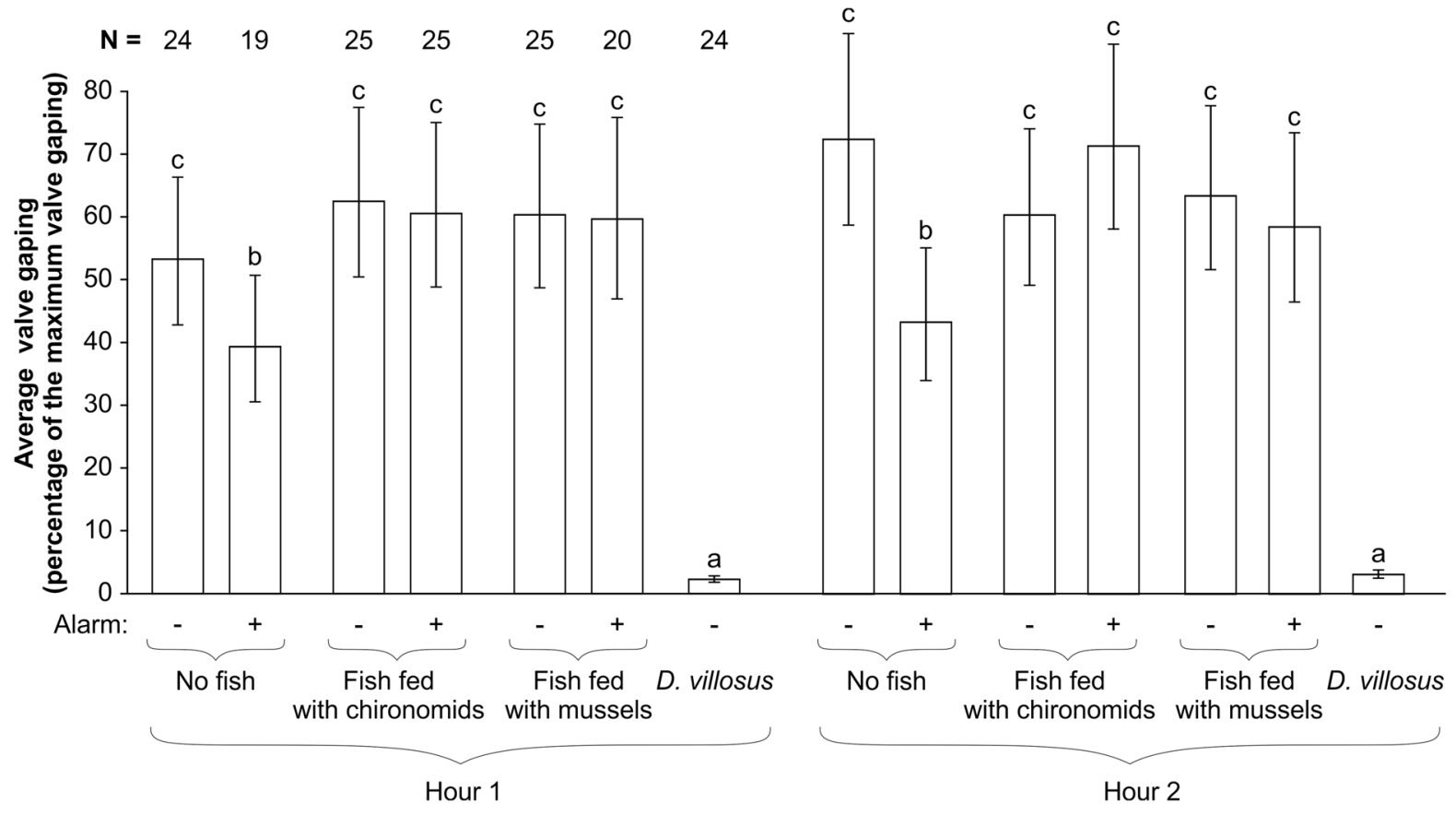

Fig. 2 Average valve gaping of zebra mussels responding to the presence and diet of predators (fish), conspecific alarm substance (present: + , absent: - ) and gammarid (D. villosus) cues. Presented values are means predicted for significant effects by the General Linear Model $( \pm 95 \%$ confidence intervals). Treatments labelled with the same letter above the bar did not differ from one another with regard to the average valve gaping (within each experimental hour) (see Supplementary Table S1 for the full results of the post hoc analysis). N indicates the number of replicates

Table 1 Analyses of the zebra mussel valve movement parameters in response to the presence and diet of fish, conspecific alarm substance and gammarid (D. villosus) cues

\begin{tabular}{|c|c|c|c|c|c|}
\hline Response variable & Effect & $d f$ & MS & $F$ & $P$ \\
\hline \multirow{3}{*}{$\begin{array}{l}\text { A. Average valve gaping ( } \% \text { of the maximum } \\
\text { valve gaping) (GLM) }\end{array}$} & Treatment & 6,154 & 66.2 & 175.50 & $<0.001$ \\
\hline & Experiment duration & 1,154 & 1.2 & 6.69 & 0.011 \\
\hline & Interaction & 6,154 & 0.2 & 1.30 & 0.258 \\
\hline \multirow[t]{3}{*}{ B. Time spent with totally closed valves (GLM) } & Treatment & 6,154 & 164.0 & 68.79 & $<0.001$ \\
\hline & Experiment duration & 1,154 & 11.0 & 4.35 & 0.039 \\
\hline & Interaction & 6,154 & 7.8 & 3.10 & 0.007 \\
\hline \multirow{3}{*}{$\begin{array}{l}\text { C. Time spent with narrowly open valves } \\
(<20 \% \text { of the maximum gaping) (GLM) }\end{array}$} & Treatment & 6,154 & 79.2 & 31.14 & $<0.001$ \\
\hline & Experiment duration & 1,154 & 6.8 & 3.44 & 0.066 \\
\hline & Interaction & 6,154 & 3.9 & 1.96 & 0.075 \\
\hline \multirow{3}{*}{$\begin{array}{l}\text { D. Time spent with widely open valves }(>80 \% \\
\text { of the maximum gaping) (GLM) }\end{array}$} & Treatment & 6,154 & 203.1 & 132.69 & $<0.001$ \\
\hline & Experiment duration & 1,154 & $<0.1$ & 0.02 & 0.895 \\
\hline & Interaction & 6,154 & 1.7 & 1.36 & 0.234 \\
\hline \multirow[t]{3}{*}{ E. Number of valve opening movements (GLZ) } & Treatment & 6,302 & & 15.31 & $<0.001$ \\
\hline & Experiment duration & 1,302 & & 1.19 & 0.277 \\
\hline & Interaction & 6,302 & & 0.57 & 0.751 \\
\hline
\end{tabular}

Experiment duration (the first or second hour of the trial) is included in the models as a repeated measures factor $G L M$ general linear model, GLZ generalized linear model 

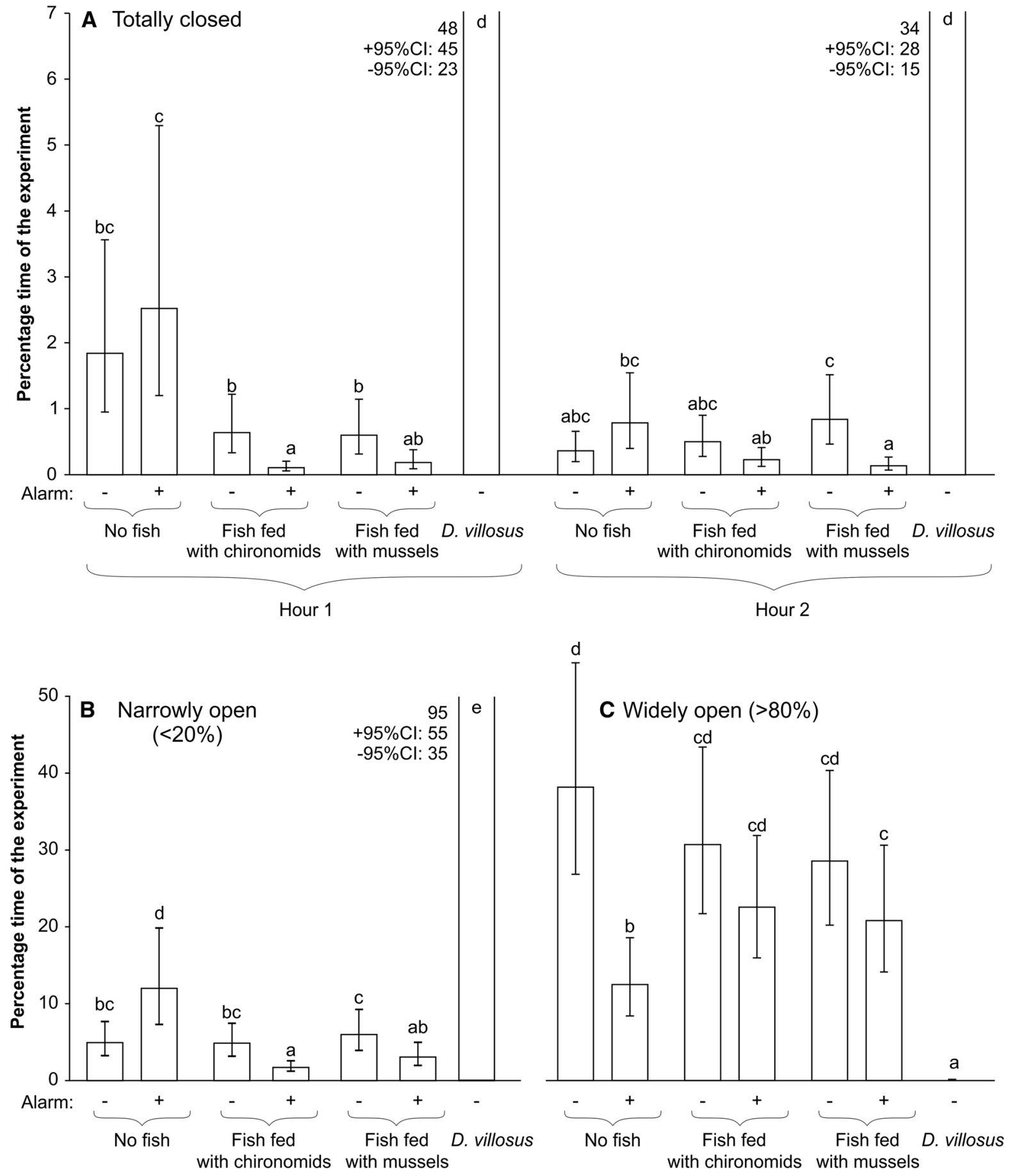

Fig. 3 Percentage time spent by zebra mussels at particular gaping ranges during exposure to the presence and diet of predators (fish), conspecific alarm substance (present: + , absent: -) and gammarid (D. villosus) cues. Presented values are means predicted for significant effects by the General Linear Model
( $\pm 95 \%$ confidence intervals). Treatments labelled with the same letter above the bar did not differ from one another with regard to the time spent at the particular valve gaping range (within each experimental hour, if separated) (see Supplementary Tables S2-S4 for the full results of the post hoc analyses) 


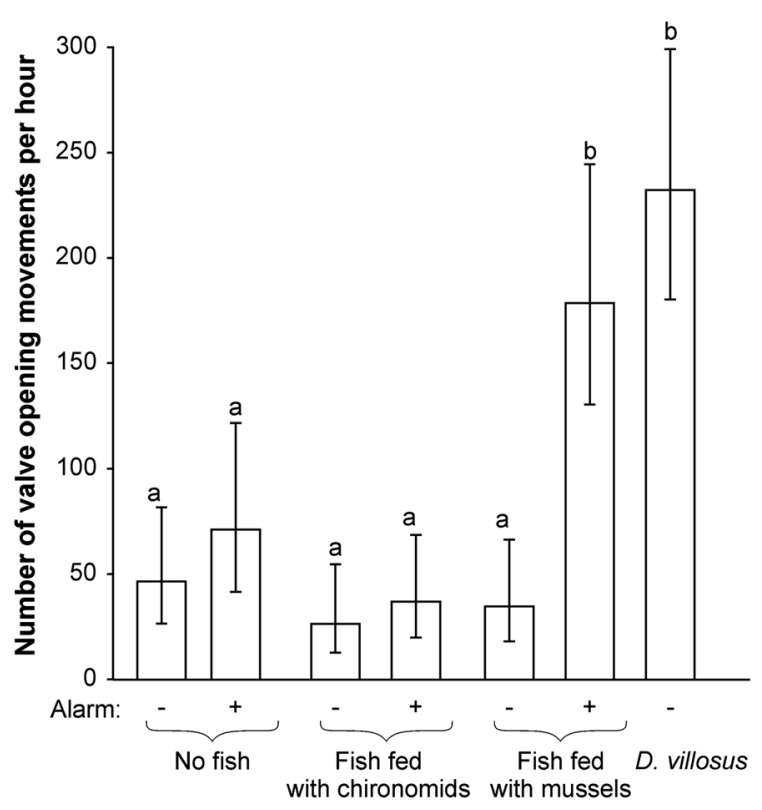

Fig. 4 Numbers of valve opening movements exhibited by zebra mussels responding to the presence and diet of predators (fish), conspecific alarm substance (present: + , absent: - ) and gammarid (D. villosus) cues. Presented values are means predicted for significant effects by the Generalized Linear Model ( $\pm 95 \%$ confidence intervals). Treatments labelled with the same letter above the bar did not differ from one another (see Supplementary Table S5 for the full results of the post hoc analysis)

h. This parameter significantly depended on experimental treatment, but not on duration of the test (Generalized Linear Model: Table 1E). The mussels tested in the presence of gammarids (232 movements/ $\mathrm{h}$ ), as well as those exposed to the mixture of the scent of fish fed with mussels and the alarm substance (179 movements/h) were generally more active than in the other treatments (35-71 movements/h) (Fig. 4).

\section{Discussion}

The most influential factors in our study turned out to be the physical presence of D. villosus [which naturally occurs in D. polymorpha colonies (Devin et al., 2003)] and the alarm substance excreted by injured conspecifics. Mussel responses to these factors were of similar character; however, the effect of the mechanical stimulus was much greater than that of the chemical predation cue. D. polymorpha exposed to gammarids spent most of the time with totally closed or narrowly open valves $(<20 \%)$, which resulted in the very narrow average valve gaping during the entire experiment. Visual inspection of the video recordings revealed that these strong behavioural reactions were likely connected with the protection of siphons and other exposed soft tissues against mechanical irritation by $D$. villosus appendages. The longer-term impact of D. villosus on D. polymorpha was reported by Kobak et al. (2012), who observed that mussels in the presence of amphipods increased their attachment strength and reduced upward movement. Moreover, D. villosus is considered to be a voracious and aggressive carnivore (Kley \& Maier, 2005; BacelaSpychalska et al., 2013). These features are associated with its direct and indirect negative impact on other amphipods (Bij de Vaate et al., 2002; Devin et al., 2003; MacNeil et al., 2013; Jermacz et al., 2015) and even fish fry (Platvoet et al., 2009). However, it has not been demonstrated to attack $D$. polymorpha directly, except one observation of gammarids feeding on mussel byssal threads (Platvoet et al., 2009). Thus, it is unlikely that $D$. villosus could pose a direct predatory threat to mussels. Nevertheless, taking into account the results of the present study, we assume that a prolonged exposure to its high density may negatively affect $D$. polymorpha condition.

In contrast to $D$. villosus, the presence of the alarm substance in the environment definitely indicates a direct and immediate danger, i.e. the proximity of a foraging predator (Wisenden, 2015). In our study, mussels exposed to this cue significantly reduced their average valve gaping and time spent with widely open valves ( $>80 \%)$. This behaviour does not defend them during a direct attack of a shell-crushing predator, but can prevent detection by limiting the amount of infochemicals released from the exposed mantle surface and siphonal currents generated during filtration (Weissburg et al., 2002; Smee \& Weissburg, 2006; Antoł et al., 2018). Similarly to our results, Robson et al. (2007, 2010) revealed that another bivalve species, Mytilus edulis Linnaeus, 1758 in the presence of predation risk (alarm cue) demonstrated smaller gape angles. Moreover, in the presence of the alarm cue, mytilids closed their valves more rapidly and became less responsive to food. Strong behavioural responses to alarm cues have also been described for many freshwater animals (Wisenden \& Millard, 2001; Wisenden et al., 2001; Dalesman et al., 2006; Smee \& Weissburg, 2006), indicating the 
importance of this factor in shaping animal behaviour. Predator foraging activity can be triggered by chemical signals from metabolically active mussels (Czarnołęski et al., 2011), which further supports the protective value of valve gaping reduction.

The reduced valve gaping of $D$. polymorpha exposed to the alarm cues, found in our study, corroborates previous observations, revealing that byssate mussels during the first few hours of exposure to predation cues reduce their attachment (Reimer \& Tedengren, 1997) travelled distances (Toomey et al., 2002; Czarnołęski et al., 2010) and respiration rates (Antoł et al., 2018). All these responses lead to decreased probability of detection of mussels by predators (Antoł et al., 2018). However, after the initial activity reduction, mussels exposed to predation cues were found to relocate more than in the control treatment (Kobak \& Ryńska, 2014) and attach more strongly to substratum (Reimer \& Tedengren, 1997; Kobak et al., 2010), indicating the importance of time factor for shaping animal responses to danger cues.

For most of the analysed valve movement parameters we did not reveal any specific effects of the predator (the roach $R$. rutilus) scent itself, separated from conspecific alarm cues, regardless of the differences in the roach diet. In a previous experimental study, Kobak et al. (2010) demonstrated that mussels were capable of recognizing the scent of roach (fed with neutral chironomid diet) and in response to this stimulus attached more strongly to the substratum, though the effect appeared after 6 days of exposure. These findings show that mussels can adjust their antipredator strategy depending on the exposure time and proximity of the danger. Their immediate responses to direct dangers (currently hunting predators indicated by the presence of the conspecific alarm cue) involve activity decrease aimed at hiding the prey presence from the predator (Reimer \& Tedengren, 1997; Czarnołęski et al., 2010; Antoł et al., 2018). When a danger is indirect (a non-foraging predator releasing only kairomones) and/or exposure lasts for a longer time, different mechanisms become involved, increasing the mussel security through stronger attachment (Reimer \& Tedengren, 1997), aggregation (Kobak et al., 2010) and/or development of thicker shells (Czarnołęski et al., 2006; Naddafi \& Rudstam, 2014). Changes in valve movements seem to be the first behavioural reaction exhibited immediately after detecting predatory cues, but only in the case of a direct threat (as the alarm substance in our experiments). The alarm cue in the direct vicinity may be treated as a sign of an immediate danger by mussels, with no time to employ more sophisticated and timeconsuming defence mechanisms. On the other hand, valve gaping reduction in response to indirect and/or long-term predation danger would be too costly, limiting respiration and feeding (Jørgensen et al., 1988), whereas the presence of some numbers of predators in the environment is a natural situation in the wild.

In our study, mussels exposed to the alarm cues spent more time with totally closed or only narrowly open valves $(<20 \%)$ which was probably insufficient for effective filtration (Jørgensen et al., 1988; Newell et al., 1998; Robson et al., 2010), as at this degree of valve opening they were unable to extend their siphons (personal observation). This narrow valve opening could be related to a compromise between hiding and sustaining respiration (impossible during the complete closure) or to periodic "testing the external environment" in a stress situation. The latter hypothesis is also supported by another reaction of mussels exposed to alarm cues in our study: the increased number of valve opening movements. This seems useful, as completely closed mussels have impaired sensory contact with the external environment and, being unable to sustain filter-feeding and aerobic respiration, bear severe costs of non-consumptive predation effects. Thus, although D. polymorpha can stay closed even for several days protecting themselves against unfavourable environmental conditions (Rajagopal et al., 2010), it is beneficial if they can quickly detect a positive change in their environment and return to their normal activity as soon as possible.

Another interesting phenomenon observed in our study concerns the reactions of mussels to the scent of fish mixed with the alarm substance and/or dietary alarm cue. We supposed these separate predation cues to act synergistically and elicit stronger mussel responses than each of them applied separately (Dalesman et al., 2006). In contrast to this expectation, the compound stimulus (i.e. the conspecific alarm substance combined with predator scent) made mussels spend less time with the totally closed or narrowly open valves compared to the treatments with separate alarm cue and fish scents. On the other hand, mussels exposed to the mixture of the alarm cue and the scent of a predator fed with conspecifics still showed the 
increased number of valve movements, similar to that exhibited by the individuals exposed to the alarm cue alone. Nevertheless, the response of mussels to the mixed predation cue was clearly weaker than that observed in the presence of the alarm substance alone and actually more similar to the results of the control treatment. Taking into account the fact that we always used the same amount of the alarm cue, the change in its effect on mussel behaviour must have been caused by the presence of fish infochemicals. Perhaps, the predator might be able to mask the components of alarm cues (including those originating from its faeces containing the remnants of digested mussels). It should be noted that, in the first hour of experiment, the control mussels tended to be totally closed for a longer time than those exposed to the fish scents. This might point to the fact that they were still adapting to the experimental conditions, whereas this effect did not occur in the presence of fish scents, potentially supporting our hypothesis on their masking effect on stressors influencing mussel behaviour. Anyway, further experimental evidence is needed to disentangle this observation. A similar phenomenon was suggested by Wisenden (2015) but only for dietary alarm cues (postingestion cues released by the predator, the northern pike Esox lucius) of the ruffe (Gymnocephalus cernuus) (Maniak et al., 2000). Similarly, Feminella \& Hawkins (1994) observed that tadpoles of the tailed frog (Ascaphus truei) were unable to detect the presence of their predator, the shorthead sculpin (Cottus confusus) fed with conspecific tadpoles, whereas other predator species were recognized. It is not known, however, whether the tadpoles can respond to the scent of the conspecific alarm cues alone. Thus, to our knowledge, our work is the first to suggest an interaction between predator infochemicals and alarm cues released by wounded prey resulting in the weakening of the prey response. Definitely, this phenomenon deserves further research to explain its mechanisms.

\section{Conclusion}

We have shown that biotic environmental factors, such as predation alarm cues and mechanical irritation by mobile dwellers of a mussel bed, may significantly affect $D$. polymorpha valve movements. This points to potential negative non-consumptive effects on mussels, disrupting their normal filtration and respiration activity. Due to the common occurrence of both stimuli in the wild, we can expect that they may have a real influence on the functioning of mussel colonies, including their filtration (which varies with the degree of valve opening, Jørgensen et al., 1988; Newell et al., 1998; Saurel et al., 2007), being one of the most important aspects of their environmental impact. The decrease in filtration efficiency in the presence of predators was demonstrated by Naddafi et al. (2007). Thus, colony filtration rates may be overestimated if these factors are not taken into account.

Our study together with the existing literature (Naddafi et al., 2007; Shin et al., 2008; Cheung et al., 2009; Czarnołęski et al., 2010; Kobak et al., 2010; Naddafi \& Rudstam, 2013; Antoł et al., 2018) shows that sessile organisms are capable of fine-tuning their responses to specific situations involving variable predation pressure, taking multiple factors, such as the vicinity and condition of a predator as well as duration of exposure into account. Although unable to escape from environmental dangers and having limited possibilities of selecting their location, they can use a variety of behavioural responses to avoid detection by predators and/or to make their handling more difficult.

Additionally, our findings show that in behavioural studies on mussel valve movements special attention should be paid to subtle, non-binary valve reactions, which can reveal responses invisible when only two valve states (open/closed) are considered. Thus, our study may also be important for the development of early warning systems detecting environmental pollution on the basis of mussel valve movement patterns (Kramer et al., 1989; Borcherding, 2006; Robson et al., 2007; Redmond et al., 2017). Such non-target factors as predation pressure should be taken into account when calibrating these systems to avoid false alarms.

Several questions raised by our present study still await answers to be given by future research, the most important being valve movement responses to the studied factors over a longer time scale (e.g. after several days of exposure) and the mechanism behind the observed reduction in the effect of the alarm cue in the presence of fish.

Acknowledgements Our study was supported by a grant of the Polish National Science Centre No. 2015/17/N/NZ8/01653. 
Open Access This article is distributed under the terms of the Creative Commons Attribution 4.0 International License (http:// creativecommons.org/licenses/by/4.0/), which permits unrestricted use, distribution, and reproduction in any medium, provided you give appropriate credit to the original author(s) and the source, provide a link to the Creative Commons license, and indicate if changes were made.

\section{References}

Antoł, A., J. Kierat \& M. Czarnoleski, 2018. Sedentary prey facing an acute predation risk: testing the hypothesis of inducible metabolite emission suppression in zebra mussels, Dreissena polymorpha. Hydrobiologia 810: 109-117.

Bacela-Spychalska, K., M. Grabowski, T. Rewicz, A. Konopacka \& R. Wattier, 2013. The 'killer shrimp' Dikerogammarus villosus (Crustacea, Amphipoda) invading Alpine lakes: overland transport by recreational boats and scuba-diving gear as potential entry vectors? Aquatic Conservation: Marine and Freshwater Ecosystems 23: 606-618.

Beggel, S., J. Brandner, A. F. Cerwenka \& J. Geist, 2016. Synergistic impacts by an invasive amphipod and an invasive fish explain native gammarid extinction. BMC Ecology 16: 32.

Bij de Vaate, A., K. Jazdzewski, H. A. Ketelaars, S. Gollasch \& G. van der Velde, 2002. Geographical patterns in range extension of Ponto-Caspian macroinvertebrate species in Europe. Canadian Journal of Fisheries and Aquatic Sciences 59: 1159-1174.

Borcherding, J., 2006. Ten years of practical experience with the Dreissena-Monitor, a biological early warning system for continuous water quality monitoring. Hydrobiologia 556: 417-426.

Botts, P. S., B. A. Patterson \& D. W. Schloesser, 1996. Zebra mussel effects on benthic invertebrates: physical or biotic? Journal of the North American Benthological Society 15: 179-184.

Bryan, P. J., J. L. Kreider \& P. Y. Qian, 1998. Settlement of the serpulid polychaete Hydroides elegans (Haswell) on the arborescent bryozoan Bugula neritina (L.): evidence of a chemically mediated relationship. Journal of Experimental Marine Biology and Ecology 220: 171-190.

Cheung, S. G., F. Y. Yang, J. M. Y. Chiu, C. C. Liu \& P. K. Shin, 2009. Anti-predator behaviour in the green-lipped mussel Perna viridis: byssus thread production depends on the mussel's position in clump. Marine Ecology Progress Series 378: 145-151.

Chivers, D. P., B. D. Wisenden \& R. J. F. Smith, 1996. Damselfly larvae learn to recognize predators from chemical cues in the predator's diet. Animal Behaviour 52: 315-320.

Czarnołęski, M., J. Kozłowski, P. Kubajak, K. Lewandowski, T. Müller, A. Stańczykowska \& K. Surówka, 2006. Crosshabitat differences in crush resistance and growth pattern of zebra mussels (Dreissena polymorpha): effects of calcium availability and predator pressure. Archiv für Hydrobiologie 165: 191-208.
Czarnołęski, M., T. Müller, K. Adamus, G. Ogorzelska \& M. Sog, 2010. Injured conspecifics alter mobility and byssus production in zebra mussels Dreissena polymorpha. Fundamental and Applied Limnology/Archiv für Hydrobiologie 176: 269-278.

Czarnołęski, M., T. Müller, J. Kierat, L. Gryczkowski \& L. Chybowski, 2011. Anchor down or hunker down: an experimental study on zebra mussels' response to predation risk from crayfish. Animal Behaviour 82: 543-548.

Dahms, H. U., T. Harder \& P. Y. Qian, 2004. Effect of meiofauna on macrofauna recruitment: settlement inhibition of the polychaete Hydroides elegans by the harpacticoid copepod Tisbe japonica. Journal of Experimental Marine Biology and Ecology 311: 47-61.

Dalesman, S., S. D. Rundle, R. A. Coleman \& P. A. Cotton, 2006. Cue association and antipredator behaviour in a pulmonate snail, Lymnaea stagnalis. Animal Behaviour 71: 789-797.

Devin, S., C. Piscart, J. N. Beisel \& J. C. Moreteau, 2003. Ecological traits of the amphipod invader Dikerogammarus villosus on a mesohabitat scale. Archiv für Hydrobiologie 158: 43-56.

Feminella, J. W. \& C. P. Hawkins, 1994. Tailed frog tadpoles differentially alter their feeding behavior in response to non-visual cues from four predators. North American Benthological Society 13: 310-320.

Ferrari, M. C. O., A. Sih \& D. P. Chivers, 2009. The paradox of risk allocation: a review and prospectus. Animal Behaviour 78: 579-585.

García-March, J. R., M. A. Sanchís Solsona \& A. M. GarcíaCarrascosa, 2008. Shell gaping behaviour of Pinna nobilis L., 1758: circadian and circalunar rhythms revealed by in situ monitoring. Marine Biology 153: 689-698.

Gierszewski, P., 2006. Warunki przepływu wód przez Zbiornik Włocławski (Conditions of the water flow through the Włocławek Dam Reservoir). In Olszewski A. \& K. Chutkowski (eds), Drogami wędrówek i badań Profesora Rajmunda Galona w 100. rocznicę urodzin (1906-2006). Przewodnik sesji terenowych, Oficyna Wydawnicza Turpress, Toruń, Poland: 250-254.

Gosling, E., 2003. Bivalve Molluscs: Biology, Ecology and Culture. Blackwell Publishing, Oxford.

Hill, M. S., N. A. Lopez \& K. A. Young, 2005. Anti-predator defenses in western North Atlantic sponges with evidence of enhanced defense through interactions between spicules and chemicals. Marine Ecology Progress Series 291: 93-102.

Jermacz, Ł., A. Dzierżyńska, T. Kakareko, M. Poznańska \& J. Kobak, 2015. The art of choice: predation risk changes interspecific competition between freshwater amphipods. Behavioral Ecology 26: 656-664.

Jermacz, Ł., A. Dzierżyńska-Białończyk \& J. Kobak, 2017. Predator diet, origin or both? Factors determining responses of omnivorous amphipods to predation cues. Hydrobiologia 785(1): 173-184.

Jørgensen, C. B., P. S. Larsen, F. Møhlenberg \& H. U. Riisgård, 1988. The mussel pump: properties and modelling. Marine Ecology Progress Series 45: 205-216.

Khalaman, V. V., 2001. Succession of fouling communities on an artificial substrate of a mussel culture in the White Sea. Russian Journal of Marine Biology 27: 345-352. 
Kilgour, B. W. \& M. A. Baker, 1994. Effects of season, stock, and laboratory protocols on survival of zebra mussels (Dreissena polymorpha) in bioassays. Archives of Environmental Contamination and Toxicology 27: 29-35.

Kley, A. \& G. Maier, 2005. An example of niche partitioning between Dikerogammarus villosus and other invasive and native gammarids: a field study. Journal of Limnology 64: 85-88.

Kobak, J. \& T. Kakareko, 2009. Attachment strength, aggregation and movement of the zebra mussel (Dreissena polymorpha, Bivalvia) in the presence of potential predators. Fundamental and Applied Limnology/Archiv für Hydrobiologie 174: 193-204.

Kobak, J. \& A. Ryńska, 2014. Environmental factors affecting behavioural responses of an invasive bivalve to conspecific alarm cues. Animal Behaviour 96: 177-186.

Kobak, J., T. Kakareko \& M. Poznańska, 2010. Changes in attachment strength and aggregation of zebra mussel, Dreissena polymorpha in the presence of potential fish predators of various species and size. Hydrobiologia 644: 195-206.

Kobak, J., M. Poznańska \& T. Kakareko, 2012. Behavioural changes of zebra mussel Dreissena polymorpha (Bivalvia) induced by Ponto-Caspian gammarids. Biological Invasions 14: 1851-1863.

Kramer, K. J. M. \& E. M. Foekema, 2001. The "Musselmonitor $^{\circledR}$ " as biological early warning system: the first decade. In Butterworth, F. M., A. Gunatilaka \& M. E. Gonsebatt (eds), Biomonitors and Biomarkers as Indicators of Environmental Change 2. A Handbook. Springer, New York: 59-87.

Kramer, K. J. M., H. A. Jenner \& D. de Zwart, 1989. The valve movement response of mussels: a tool in biological monitoring. Hydrobiologia 188-189: 433-443.

Large, S., P. Torres \& D. Smee, 2012. Behavior and morphology of Nucella lapillus influenced by predator type and predator diet. Aquatic Biology 16: 189-196.

Lima, S. L. \& L. M. Dill, 1990. Behavioral decisions made under the risk of predation: a review and prospectus. Canadian Journal of Zoology 68: 619-640.

MacNeil, C., P. Boets, K. Lock \& P. L. M. Goethals, 2013. Potential effects of the invasive "killer shrimp" (Dikerogammarus villosus) on macroinvertebrate assemblages and biomonitoring indices. Freshwater Biology 58: 171-182.

Maniak, P. J., R. D. Lossing \& P. W. Sorensen, 2000. Injured Eurasian ruffe, (Gymnocephalus cernuus), release an alarm pheromone that could be used to control their dispersal. Journal of Great Lakes Research 26: 183-195.

Naddafi, R. \& L. G. Rudstam, 2013. Predator-induced behavioural defences in two competitive invasive species: the zebra mussel and the quagga mussel. Animal Behaviour 86: $1275-1284$.

Naddafi, R. \& L. G. Rudstam, 2014. Predator-induced morphological defences in two invasive dreissenid mussels: implications for species replacement. Freshwater Biology 59: 703-713.

Naddafi, R., P. Eklöv \& K. Pettersson, 2007. Non-lethal predator effects on the feeding rate and prey selection of the exotic zebra mussel Dreissena polymorpha. Oikos 116: 1289-1298.
Newell, C. R., D. E. Campbell \& S. M. Gallagher, 1998. Development of the mussel aquaculture lease site model MUSMOD: a field program to calibrate model formulations. Journal of Experimental Marine Biology and Ecology 219: 143-169.

Platvoet, D., J. T. A. Dick, C. MacNeil, M. C. van Riel \& G. van der Velde, 2009. Invader-invader interactions in relation to environmental heterogeneity leads to zonation of two invasive amphipods, Dikerogammarus villosus (Sowinsky) and Gammarus tigrinus Sexton: amphipod pilot species project (AMPIS) report 6. Biological Invasions 11: 2085-2093.

Prejs, A., K. Lewandowski \& A. Stańczykowska-Piotrowska, 1990. Size-selective predation by roach (Rutilus rutilus) on zebra mussel (Dreissena polymorpha): field studies. Oecologia 83: 378-384.

Rajagopal, S., G. van der Velde \& H. A. Jenner, 1997. Shell valve movement response of dark false mussel, Mytilopsis leucophaeta, to chlorination. Water Research 31: 3187-3190.

Rajagopal, S., G. van der Velde \& H. A. Jenner, 2010. Chlorination for Dreissena polymorpha control: old war-horse for the new pest? In Van der Velde, G., S. Rajagopal \& A. Bij de Vaate (eds), The Zebra Mussel in Europe. Backhuys Publishers/Margraf Publishers, Leiden/Weikersheim: 383-392.

Redmond, K. J., M. Berry, D. M. Pampanin \& O. K. Andersen, 2017. Valve gape behaviour of mussels (Mytilus edulis) exposed to dispersed crude oil as an environmental monitoring endpoint. Marine Pollution Bulletin 117: 330-339.

Reimer, O. \& M. Tedengren, 1997. Predator-induced changes in byssal attachment, aggregation and migration in the blue mussel, Mytilus edulis. Marine and Freshwater Behaviour and Physiology 30: 251-266.

Riisgård, H. U., C. Kittner \& D. F. Seerup, 2003. Regulation of opening state and filtration rate in filter-feeding bivalves (Cardium edule, Mytilus edulis, Mya arenaria) in response to low algal concentration. Journal of Experimental Marine Biology and Ecology 284: 105-127.

Robson, A., R. Wilson \& C. Garcia De Leaniz, 2007. Mussels flexing their muscles: a new method for quantifying bivalve behaviour. Marine Biology 151: 1195-1204.

Robson, A. A., C. Garcia De Leaniz, R. P. Wilson \& L. G. Halsey, 2010. Behavioural adaptations of mussels to varying levels of food availability and predation risk. Journal of Molluscan Studies 76: 348-353.

Saurel, C., J. C. Gascoigne, M. R. Palmer \& M. J. Kaiser, 2007. In situ mussel feeding behavior in relation to multiple environmental factors: regulation through food concentration and tidal conditions. Limonology and Oceanography 52: 1919-1929.

Schmidt-Drewello, A., H. W. Riss, J. P. Scharsack \& E. I. Meyer, 2016. Relative benefit of the invasive Echinogammarus berilloni (Catta, 1878) over native gammarids under fish predation (Gasterosteus aculeatus Linnaeus, 1758). Aquatic Ecology 50: 75-85.

Shin, P. K. S., C. C. Liu, Z. X. Liu \& S. G. Cheung, 2008. Marine mussels Brachidontes variabilis selected smaller places of refuge and enhanced byssus production upon exposure to conspecific and heterospecific cues. Journal of Experimental Marine Biology and Ecology 361: 16-20. 
Smee, D. L. \& M. J. Weissburg, 2006. Hard clams (Mercenaria mercenaria) evaluate predation risk using chemical signals from predators and injured conspecifics. Journal of Chemical Ecology 32: 605-619.

Sousa, R., J. L. Gutiérrez \& D. C. Aldridge, 2009. Nonindigenous invasive bivalves as ecosystem engineers. Biological Invasions 11: 2367-2385.

Toomey, M. B., D. McCabe \& J. E. Marsden, 2002. Factors affecting the movement of adult zebra mussels (Dreissena polymorpha). Journal of the North American Benthological Society 21: 468-475.

Turner, A. M., S. E. Turner \& H. M. Lappi, 2006. Learning, memory and predator avoidance by freshwater snails: effects of experience on predator recognition and defensive strategy. Animal Behaviour 72: 1443-1450.

Weissburg, M. J., M. C. Ferner, D. P. Pisut \& D. L. Smee, 2002. Ecological consequences of chemically mediates prey perception. Journal of Chemical Ecology 28: 1953-1970.

Wisenden, B. D., 2015. Chemical cues that indicate risk of predation. In Sorensen, P. W. \& B. D. Wisenden (eds), Fish
Pheromones and Related Cues. Wiley, Chichester: 131-148.

Wisenden, B. D. \& M. C. Millard, 2001. Aquatic flatworms use chemical cues from injured conspecifics to assess predation risk and to associate risk with novel cues. Animal Behaviour 62: 761-766.

Wisenden, B. D., S. G. Pohlman \& E. E. Watkin, 2001. Avoidance of conspecific injury-released chemical cues by free-ranging Gammarus lacustris (Crustacea: Amphipoda). Journal of Chemical Ecology 27: 1249-1258.

Wudkevich, K., B. D. Wisenden, D. P. Chivers \& J. F. Smith, 1997. Reactions of Gammarus lacustris to chemical stimuli from natural predators and injured conspecifics. Journal of Chemical Ecology 23: 1163-1173.

Publisher's Note Springer Nature remains neutral with regard to jurisdictional claims in published maps and institutional affiliations. 